\title{
JURISPRUDÊNCIA E PRECEDENTES NO DIREITO BRASILEIRO: PANORAMA E PERSPECTIVAS ${ }^{1}$
}

\section{JURISPRUDENCE AND PRECEDENTS IN BRAZILIAN LAW: OVERVIEW AND PERSPECTIVES}

Aluisio Gonçalves de Castro Mendes Desembargador Federal. Membro da $3^{\text {a }}$ Seção e da $5^{\text {a }}$ Turma do Tribunal Regional Federal da $2^{\text {a }}$ Região (TRF-2). Integrante do Conselho Consultivo do Departamento de Pesquisas Judiciárias (DPJ) e dos Grupos de Trabalho do Conselho Nacional de Justiça (CNJ) para o fortalecimento dos precedentes e para a modernização e efetividade do Poder Judiciário nos processos de execução e cumprimento de sentença. Professor Titular de Direito Processual Civil da Faculdade de Direito da Universidade do Estado do Rio de Janeiro (UERJ) e do Programa de Pós-Graduação em Direito (PPGD) da Universidade Estácio de Sá (Unesa). Professor Convidado no Instituto Max Planck de Luxemburgo (2016). Professor-expositor da Escola da Magistratura do Estado do Rio de Janeiro (EMERJ). Pós-Doutor pela Universidade de Regensburg, Alemanha. Mestre e Doutor em Direito pela Universidade Federal do Paraná (UFPR). Mestre em Direito pela Johann Wolfgang Goethe Universität (Frankfurt am Main, Alemanha). Especialista em Direito Processual Civil pela Universidade de Brasília (UnB). Graduado em Direito pela Universidade do Estado do Rio de Janeiro (UERJ) e em Comunicação Social pela Pontifícia Universidade Católica do

\footnotetext{
${ }^{1}$ Artigo recebido em 27/08/2021, sob dispensa de revisão.
} 
Rio de Janeiro (PUC-RJ). Membro da Academia Brasileira de Letras Jurídicas (ABLJ). Diretor do Instituto Ibero-americano de Direito Processual (IIDP), do Instituto Brasileiro de Direito Processual (IBDP) e do Instituto Carioca de Processo Civil (ICPC). Membro da Associação Brasil-Alemanha de Juristas (Deutsch-Brasilianische Juristenvereinigung DBJV) e da International Association of Procedural Law (IAPL). Foi Membro do Conselho Superior da Escola Nacional de Formação e Aperfeiçoamento de Magistrados (Enfam) no biênio 2014-2016 e Diretor da Escola da Magistratura Regional Federal da $2^{\mathrm{a}}$ Região (EMARF) nos biênios 2011-2013, 2013-2015 e 2015-2017. Coordenador da Comissão Permanente de Processo Civil da Associação de Juízes Federais do Brasil (AJUFE). Membro do Conselho de Relações Internacionais da Revista de Processo (RePro), do Conselho de Redação da Revista de Processo Comparado (RPC), do Conselho Editorial do Centro de Estudos da Justiça Federal (CEJ) e do Editorial Board da Civil Procedure Review. Editor internacional da Revista Eletrônica de Direito Processual (REDP). Bolsista do Programa de Produtividade da Unesa. Consultor e ex-bolsista da Coordenação de Aperfeiçoamento de Pessoal de Nível Superior (Capes), do Serviço Alemão de Intercâmbio Acadêmico (Deutscher Akademischer Austauschdienst DAAD), do Conselho Nacional de Pesquisa (CNPq) e da Fundação Alexander von Humboldt (AvH). Membro da Comissão de Juristas responsável pelo acompanhamento da redação final do Projeto de novo Código de Processo Civil no Senado. Integrante do Projeto Comparative Procedural Law and Justice (CPLJ-P). Rio de Janeiro/RJ. E-mail: aluisiomendes@terra.com.br 
RESUMO. O presente artigo trata dos temas jurisprudência e dos precedentes no direito brasileiro, destacando a estruturação do sistema brasileiro de precedentes, como previsto no Código de Processo Civil de 2015, ressaltando as suas características no âmbito do Direito Processual Comparado.

PALAVRAS-CHAVE. Jurisprudência; Precedentes; Código de Processo Civil.

ABSTRACT. This paper deals with the themes of jurisprudence and precedents in Brazilian Law, highlighting the structuring of the Brazilian system of precedents, as provided for in the 2015 Code of Civil Procedure, emphasizing its characteristics in the context of Comparative Procedural Law.

KEYWORDS. Jurisprudence; Precedents; Code of Procedure Law.

\section{Jurisprudência e precedentes}

Inicialmente, cumpre ressaltar a conjugação dos dois tópicos, jurisprudência e precedentes. Até pouco tempo atrás, o posicionamento dos tribunais era conhecido através da jurisprudência, que era instituto jurídico mencionado no Código de Processo Civil, na legislação de modo geral e que remonta ao antigo debate, que foi muito desenvolvido através do Professor Limongi França, na Universidade de São Paulo, a respeito do papel da jurisprudência, se seria ou não fonte formal do Direito.

O conceito tradicional de jurisprudência era o entendimento pacífico e reiterado dos tribunais, sobre um determinado tema. Esses pilares, de entendimento reiterado e pacífico, é que podem ser, de certo modo, questionados, nos dias atuais. Primeiro, porque entendimento pacífico não pode significar somente consenso. Pelo contrário, as grandes questões jurídicas sempre foram objeto de polêmica. O "pacífico" significava, na verdade, o estabelecimento de um entendimento no tribunal, que pode ser por uma maioria mais larga ou menor. 
Para se aferir a reiteração do posicionamento, a metodologia era baseada na observação das decisões do tribunal, ou dos tribunais a nível local ou nacional, tentando-se verificar se os órgãos do respectivo tribunal repetiam a conclusão em repetidos julgados.

Porém, o Direito Processual sofreu modificações e o Código de Processo Civil de 2015 acabou reforçando essa alteração.

A modificação ocorreu no momento e no modo em que se fixa o entendimento dos tribunais, quando começou a haver mais julgamentos ou procedimentos concentrados, para se firmar o entendimento do tribunal sobre determinada questão. É um caminho que se iniciou, no âmbito constitucional, com as Ações Diretas de Inconstitucionalidade (ADIn) e Constitucionalidade (ADC), que foram reforçadas na Constituição de 1988 e, a partir de 1993, se estabelecendo expressamente o efeito erga omnes dessas decisões, através da respectiva emenda constitucional.

Então, se o Supremo Tribunal Federal possui reiterados julgados na Primeira ou na Segunda Turmas a favor do entendimento " $\mathrm{x}$ " no passado e, posteriormente, vem uma Ação Direta de Inconstitucionalidade (ADIn) ou de Constitucionalidade (ADC) e é modificado o entendimento do Supremo, para fixar uma tese diferente, a partir de então qual é a jurisprudência do Tribunal? A resposta só pode ser o entendimento firmado na Ação Direta de Inconstitucionalidade ou de Constitucionalidade, ou seja, a partir de um único julgamento concentrado, não se exigindo, como condição sine qua non, a antiga reiteração de julgados.

Após, com a introdução de outros mecanismos, como os recursos repetitivos, a partir de 2006, no Supremo Tribunal Federal, em 2008 no Superior Tribunal de Justiça e em 2014 no Tribunal Superior do Trabalho, a possibilidade de julgamentos concentrados se ampliou consideravelmente. Finalmente, no Código de Processo Civil de 2015, foram sistematizados esses mecanismos, criado o incidente de resolução de demandas repetitivas (IRDR) e o fortalecimento do incidente de assunção de competência (IAC).

Consequentemente, houve uma modificação relevante, quanto à premissa e ao conceito, no que diz respeito à jurisprudência. O Código de Processo Civil de 2015, o Código Fux, que tive a honra de participar da Comissão de Juristas, na sua etapa final de acompanhamento no Senado, estabelece um sistema de precedentes com efeito vinculativo. Há precedentes persuasivos, mas os vinculativos são mais importantes e esse sistema 
também passa a prestigiar e a estabelecer que os precedentes qualificados advêm de procedimentos concentrados, nos recursos repetitivos, no incidente de resolução de demandas repetitivas (IRDR) e no incidente de assunção de competência (IAC).

Há uma ruptura. A jurisprudência pode advir de julgamentos reiterados proferidos, normalmente, pelos órgãos fracionários, não ensejando um precedente qualificado. Mas, pode advir também de julgamentos concentrados, a partir de procedimentos concentrados, que resultam em precedentes qualificados, nos termos do artigo 927.

Então, a jurisprudência continua podendo ser aferida a partir de instrumentos não concentrados, ou seja, da reiteração de julgados. Contudo, houve uma ampliação, para considerar os posicionamentos estabelecidos a partir de julgamentos concentrados, com a fixação de teses, precedentes qualificados, firmadas nas hipóteses elencadas no art. 927 do CPC. Há, portanto, uma zona de interseção entre precedentes e jurisprudência, mas não uma identidade absoluta.

\section{O sistema brasileiro de precedentes: um panorama}

O sistema brasileiro é mais recente, precisa ser compreendido e estudado o sistema estrangeiro, mas esse estudo, em primeiro lugar, não significa um complexo de tupiniquim e, também, não significa que o Brasil importou o sistema estrangeiro. Muito pelo contrário: a Comissão de Juristas procurou estudar e até trouxe para o seu bojo pessoas conhecedoras do sistema de precedentes, podendo-se citar a Professora Teresa Arruda Alvim, que há muito tempo estuda o tema, e eu também estudo há muito tempo, tenho muitos Doutorandos e Mestrandos que já eram estimulados a apresentar teses e dissertações.

Em relação aos precedentes, é preciso enfatizar algumas características do sistema brasileiro. O sistema brasileiro de precedentes tem algumas peculiaridades. Assinalam-se dez pontos que tentam assinalar características do sistema brasileiro de precedentes em relação ao sistema de precedentes dos países de common law:

1) O sistema brasileiro, ao contrário do common law, foi legalmente estabelecido, há normas. O sistema do common law não foi porque não é da tradição direito legislado, embora atualmente legisle muito, em virtude da recíproca aproximação entre os sistemas. É certo que alguns países possuem normas, a House of Lords já editava 
statements e hoje a Suprema Corte também o faz. Porém, o sistema brasileiro era importante de ser legalmente estabelecido, porque a Constituição prevê o primado da lei, o que afasta a alegação de eventual inconstitucionalidade na prática e deixa o sistema de precedentes mais claro para todos os profissionais do Direito e para a sociedade.

Ainda nesse primeiro ponto, o Código de Processo Civil estabeleceu não apenas um sistema de precedentes, mas um sistema de precedentes conjugado com um sistema de julgamento de questões comuns ou repetitivas, o que contribui para o conjunto do funcionamento do sistema jurídico. $\mathrm{O}$ incidente de resolução de demandas repetitivas (IRDR), por exemplo, pode ser utilizado para uma questão comum de direito material ou processual e, quando a questão é comum de direito processual, as demandas sequer precisam ser repetitivas. Podem ser diferentes, mas a questão processual é comum.

2) O sistema trabalha com precedentes qualificados, com efeito vinculativo. Não é qualquer precedente. O legislador teve o cuidado de estabelecer alguns procedimentos e hipóteses que levam ao precedente qualificado expressamente no artigo 927 do Código de Processo Civil, ao contrário do que ocorre no common law. No common law, qualquer causa pode levar ao estabelecimento de um precedente. Aqui, há a necessidade de um determinado procedimento.

3) O legislador indicou também a competência qualificada, para os órgãos colegiados que tenham função uniformizadora no tribunal. É uma diferença. Um precedente em um país de common law pode advir de um órgão que julgaria aquela causa, mas não tem uma função precípua para fixar precedentes, a função de uniformizar toda a matéria. Aqui houve essa preocupação, geralmente o plenário, órgão especial ou seções especializadas.

4) O legislador estabeleceu um procedimento concentrado em torno da identificação de questões controversas e da resolução dessas questões com a formulação de teses, o que facilita o entendimento. Na Ação Direta de Constitucionalidade (ADC) ou na Ação Direta de Inconstitucionalidade (ADIn) são questões de direito, no incidente de resolução de demandas repetitivas (IRDR) e nos recursos repetitivos também. Foi estabelecido um procedimento que tem as garantias necessárias, importantes, para que a formulação do precedente ocorra. 
5) A definição mais precisa e clara em torno do conteúdo do precedente, consubstanciado na tese e poderia até dizer, também, na ratio decidendi. Entretanto, no sistema brasileiro, como ensina a Professora Teresa Arruda Alvim, costuma-se frisar que a preocupação era a de não seguir o problema dos países de common law, porque lá só se sabe que há um precedente depois, quando um outro ou o mesmo órgão julgador vai decidir uma questão e verifica um outro caso decidido, julgado de determinado modo, aplicando o precedente.

Para se descobrir o precedente, a ratio decidendi nem sempre é fácil, porque eles não trazem à baila uma tese dizendo qual era a questão, qual foi a conclusão e quais são as circunstâncias, o sentido objetivo, e isso dificulta. Os profissionais do Direito têm de ler o acórdão e extrair a conclusão, sendo que nem sempre é fácil e há um consenso até de interpretação, trazendo dúvida do alcance, do sentido e do conteúdo do precedente.

No Brasil, procurou-se estabelecer que a questão de direito precisa estar definida, clara, desde o início, e o tribunal precisa fixar uma tese objetiva, elencando a conclusão e as circunstâncias em que aquele entendimento deve ser utilizado, porque isso facilita para o juiz e para o tribunal, para o advogado e para o estudante. $\mathrm{O}$ objetivo do precedente é a segurança jurídica. É preciso compreender qual é a interpretação firmada, que proporciona a isonomia e a economia processual.

6) Houve um reforço dos princípios. Primeiro, do princípio da publicidade, porque há a necessidade de comunicação, há um procedimento estabelecido no Código, no artigo 1.037, $\S 8^{\circ}$. Reforçou-se o princípio da ampla defesa, porque há um debate em torno da questão, com possibilidade de audiência pública, de amici cuirae, de acompanhamento pelos interessados.

Aqueles que possuem causas pendentes, já ajuizadas ou que ainda não foram nem ajuizadas, poderão tomar conhecimento e acompanhar e eventualmente o advogado colaborar no incidente de resolução de demandas repetitivas (IRDR) ou no recurso repetitivo e por isso a preocupação no recurso repetitivo de que não houvesse uma única causa, mas no mínimo duas, até mesmo três, cinco, boas petições para subsidiar os órgãos julgadores.

Também no incidente de resolução de demandas repetitivas (IRDR) se estabeleceu essa ideia, porque há um sistema e há a necessidade de comunicação das partes nos 
processos que dependem da decisão. Essa comunicação aparentemente, pela redação, deixaria a entender que a intimação é em virtude de eventual suspensão. Ela é também para eventual discussão da verificação da suspensão, mas principalmente para que as partes possam acompanhar. Se a petição do procedimento repetitivo não é boa, é a oportunidade de a parte peticionar, para a juntada de outras petições, com o fortalecimento da ampla defesa, do contraditório e da participação no procedimento concentrado.

7) A possibilidade de suspensão parcial ou total dos processos para a preservação da isonomia, da segurança jurídica e da eficácia do futuro precedente. Aqui também há uma inovação. Não há razão para se consolidar situações anti-isonômicas e, depois, haver a uniformização. Essa suspensão, que pode ser local ou nacional, pode assegurar esse resultado e a isonomia, para que não haja uma quebra de isonomia do andamento dos processos.

8) Há uma fixação de prioridade e prazo para apreciação dos incidentes de resolução de questões comuns e dos recursos repetitivos. O prazo é de 1 (hum) ano. Pode parecer muito tempo, mas uma causa julgada em um ano é um tempo razoável. Se houver uma comparação com o âmbito internacional, talvez seja um lapso muito positivo até em relação a outros países, que demoram até 4 (quatro) anos para julgar em segunda instância. Por que essa comparação? Porque fixada a tese muitas vezes se resolve facilmente a questão. Se é fixada uma tese que enseja a improcedência de julgamento de pedidos. Provavelmente os juízes estarão imediatamente julgando improcedente e encerrando a questão, ainda que haja alguns recursos, pensando-se em um direito local, de Tribunal de Justiça (TJ). Se chegar ao Superior Tribunal de Justiça (STJ), ao Tribunal Superior do Trabalho (TST), poderá mais um ano, com um total de 2 (dois) anos com definição do Superior Tribunal de Justiça ou 3 (três) anos com definição do Supremo Tribunal Federal (STF). Para isso, é importante a prioridade e o cumprimento dos prazos.

Nesse sentido, tenho a honra de participar da Comissão Gestora do Núcleo de Gerenciamento de Precedentes do meu Tribunal e está em processo de fixação, com a mudança do regimento interno, para fixar um prazo de admissibilidade de 90 (noventa) dias, porque precisamos começar a amarrar mais essas questões, para admitir rápido e depois julgar dentro do prazo. 
9) Há uma regulamentação não só da formulação como da aplicação dos precedentes, o que é positivo e uma inovação do direito brasileiro até na comparação com outros países e há uma série de hipóteses de estabelecimento de economia processual com aplicação dos precedentes após a fixação da tese, como, por exemplo, a tutela da evidência se houve o acolhimento de uma tese favorável, que decorra a procedência de uma pretensão, com a antecipação de efeitos da pretensão, ainda que não haja sequer uma sentença. Há uma economia, uma solução rápida. Também a improcedência liminar e uma série de regras de economia processual.

10) A previsão de regramento da superação e da distinção, do overruling ou distinguishing, expressões que existem no common law, mas que procuramos regular aqui, inclusive com o procedimento de revisão, de superação das teses.

Em um sistema em construção, as normas talvez dependam de alguns aspectos a serem superados. E o primeiro é uma cultura. Temos uma cultura decisionista, os juízes estão acostumados a julgar casos concretos, mas os tribunais possuem uma função uniformizadora, que precisa ser assumida e priorizada, em benefício de todos os valores da economia, da isonomia e da segurança jurídica.

Em segundo lugar, há a necessidade de clareza nos julgamentos. Para se saber o que é ratio decidendi e obiter dictum, acolhimento colegiado ou individual. A tese tem que estar clara, mostrando, com contornos, em que hipóteses deve ser aplicada e às vezes pode ser subdivida.

O Supremo Tribunal Federal (STF) e o Superior Tribunal de Justiça (STJ) já subdividiram várias teses, para que fique até a questão mais clara, com o contorno de diversas hipóteses que estão sendo analisadas.

Quando se trata de colegiado ou individual, o momento é de julgamentos colegiados, não se deve priorizar o posicionamento individual do juiz. Se há uma liminar, uma decisão monocrática, não precisa ser levada ao colegiado, mas deve ser prestigiado o entendimento do Tribunal.

E, por fim, há a cultura e a priorização do julgamento de massa, do enfrentamento de questões repetitivas, seja através dos expedientes do artigo 927, seja através de ações coletivas. 
O legislador, com 80 (oitenta) milhões, 100 (cem) milhões de processos no país, optou por priorizar a resolução de questões repetitivas, comuns. Antes, havia as Ações Diretas de Inconstitucionalidade e de Constitucionalidade, os recursos repetitivos, instrumentos sem o efeito vinculativo e apenas no âmbito dos Tribunais Superiores. No Código de Processo Civil de 2015, estabeleceram-se os precedentes qualificados nos julgamentos concentrados e, com o incidente de resolução de demandas repetitivas (IRDR) e o incidente de assunção de competência (IAC), isso foi trazido para o âmbito do segundo e do primeiro grau, para que possa estabelecer uma certeza sobre as questões polêmicas, com uma prestação jurisdicional melhor, uma rapidez, com uma duração razoável e, também, um Judiciário mais coerente e uma sociedade mais confiante na solução dos conflitos.

\section{Perspectivas}

A modificação da norma sobre a compreensão dos precedentes e da jurisprudência, sobretudo a partir do Código de Processo Civil de 2015, precisa vir a ser atrelada a uma modificação de cultura, com a substituição do decisionismo pela função uniformizadora e pacificadora dos tribunais.

Os tribunais hoje têm o dever de uniformizar a sua jurisprudência e por isso esse sistema comum de precedente. Há também uma necessidade de clareza no sistema, de coerência entre os precedentes, uma vez que, se há casos repetitivos, é necessária uma uniformização para fazer frente a uma quantidade enorme de processos.

Essa modificação não ocorre rapidamente e a modificação também precisa ser estrutural, com o papel das Cortes Superiores, que precisam julgar de forma mais seletiva e realizar a contento o papel de uniformização a nível nacional como última palavra sobre o direito constitucional e infraconstitucional e também o papel fortalecido dos tribunais de segundo grau, que começam o procedimento de uniformização com os incidentes como o incidente de resolução de demandas repetitivas (IRDR) e o incidente de assunção de competência (IAC).

A mudança começa a existir, mas ainda depende de uma modificação cultural e na prática dos tribunais, que começa a existir, mas é preciso uma série de medidas de 
Rio de Janeiro. Ano 15. Volume 22. Número 3. Setembro a Dezembro de 2021

Periódico Quadrimestral da Pós-Graduação Stricto Sensu em Direito Processual da UERJ

Patrono: José Carlos Barbosa Moreira (in mem.). ISSN 1982-7636. pp. $42-52$

www.redp.uerj.br

estruturação dos bancos de dados, de comunicação dos precedentes, do papel da inteligência artificial, da divulgação dos precedentes, do controle da observância dos precedentes, de uma série de questões que precisam ser desenvolvidas.

Saímos da primeira etapa, da criação de uma nova norma, com o Código Fux, e passamos a uma etapa de fixação desse novo sistema nas estruturas do sistema jurídico brasileiro, tanto em âmbito judicial como extrajudicial e essa será uma das grandes modificações dos próximos anos no Direito Processual brasileiro. 